\title{
HUBUNGAN POLA MAKAN DAN POLA AKTIVITAS FISIK TERHADAP KADAR GULA DARAH SEWAKTU PADA PASIEN DIABETES MELLITUS TIPE 2
}

\author{
${ }^{1}$ T. Eltrikanawati, ${ }^{2}$ Nurlaila, ${ }^{3}$ Masitoh Tampubolon \\ ${ }^{1,2,3}$ Program Studi Sarjana Keperawatan dan Pendidikan Profesi Ners, Institut Kesehatan Mitra Bunda, \\ Indonesia \\ Email: eltryikha@gmail.com
}

\begin{abstract}
ABSTRAK
Diabetes Mellitus adalah penyakit metabolik yang ditandai dengan peningkatan kadar glukosa darah (hiperglikemia) yang terjadi akibat kelainan sekresi insulin, kerja insulin atau keduanya. Faktor penyebab yang dapat mempengaruhi kadar glukosa darah antara lain pola makan dan pola aktivitas fisik. Pola makan yang tidak seimbang dan kurangnya melakukan aktivitas fisik menyebabkan meningkatnya kadar glukosa/gula darah. Rumusan masalah penelitian adalah bagaimana hubungan pola makan dan pola aktivitas fisik terhadap kadar gula darah pada pasien diabetes mellitus tipe 2. Tujuan penelitian untuk menganalisis hubungan pola makan dan pola aktivitas fisik terhadap kadar gula darah pada pasien diabetes mellitus tipe 2. Jenis penelitian adalah korelasi dengan pendekatan cross sectional dilaksanakan di Puskesmas Tiban Baru, Batam. Sampel penelitian adalah pasien dengan riwayat menderita diabetes mellitus tipe 2 berusia antara 20-79 tahun sebanyak 58 orang, dan pengambilan sampel menggunakan teknik pusposive sampling. Alat pengumpulan data menggunakan kuesioner, lembar observasi, dan alat glukometer. Uji statistik yang digunakan adalah Mann-Whitney. Hasil penelitian menunjukkan ada hubungan yang signifikan antara pola makan dan pola aktivitas fisik terhadap kadar gula darah sewaktu pada pasien diabetes mellitus tipe 2 dengan nilai p value 0,000 $(\alpha=0,05)$ untuk masing-masing variabel. Disarankan kepada penderita diabetes mellitus tipe 2 untuk mengatur dan menjaga pola makan seimbang baik jumlah, frekuensi, dan kandungan yang dikonsumsi setiap harinya dengan melakukan konsultasi di pelayanan kesehatan, melakukan aktivitas fisik secara rutin dalam kehidupan sehari-hari, serta melakukan pemeriksaan kadar gula darah mandiri secara rutin sehingga kadar gula darah dalam batas normal dan stabil.
\end{abstract}

Kata Kunci: Pola Makan, Pola Aktivitas Fisik, Kadar Gula Darah, Diabetes Mellitus Tipe 2.

\section{ABSTRACT}

Diabetes Mellitus is a metabolic disease characterized by increased blood glucose levels (hyperglycemia) that occurs due to abnormalities in insulin secretion, insulin action or both. Causative factors that can affect blood glucose levels include diet and physical activity patterns. Unbalanced diet and lack of physical activity lead to increased levels of glucose / blood sugar. The formulation of the research problem is how the relationship between diet and physical activity patterns on blood sugar levels in type 2 diabetes mellitus patients. The aim of the study was to analyze the relationship between diet and physical activity patterns on blood sugar levels in type 2 diabetes mellitus patients. The cross sectional approach was carried out at Puskesmas Tiban Baru, Batam. The study sample was 58 patients with a history of suffering from type 2 diabetes mellitus aged 20-79 years, and the sample was taken using purposive sampling technique. The data collection tools used questionnaires, observation sheets, and a glucometer. The statistical test used was the Mann-Whitney test. The results showed that there was a significant relationship between diet and physical activity patterns on blood sugar levels in patients with type 2 diabetes mellitus with a $p$ value of $0.000(\alpha=0.05)$ for each variable. It is recommended for people with type 2 diabetes mellitus to regulate and maintain a balanced diet in terms of quantity, frequency, and content consumed every day by conducting consultations at health services, carrying out regular physical activity in everyday life, and checking blood sugar levels at any time. regularly so that blood sugar levels are within normal limits and stable.

Keywords: Diet, Physical Activity Pattern, Blood Sugar Levels, Type 2 Diabetes Mellitus. 


\section{PENDAHULUAN}

Diabetes Mellitus (DM) merupakan penyakit metabolik yang ditandai oleh hiperglikemi akibat kegagalan sekresi insulin, kerja insulin atau keduanya. Penyakit ini bersifat kronis dan jumlah penderitanya selalu mengalami peningkatan di seluruh dunia dan sejalan dengan bertambahnya jumlah populasi, usia, angka obesitas, dan penurunan aktivitas fisik. Kencing Manis atau Diabetes Mellitus (DM) merupakan penyakit metabolisme yang ditandai dengan meningkatnya kadar gula darah (glukosa) seseorang di dalam tubuh yang tinggi melebihi batas normal (hyperglycemia). Kadar gula yang tinggi dikeluarkan melalui air seni (urine), sehingga air seni mengandung gula atau manis sehingga disebut penyakit kencing manis. Kencing manis pada akhirnya bisa menimbulkan komplikasi baik akut maupun kronis (Marewa, 2015). Tipe DM berdasarkan pada etiologi atau faktor penyebab, berdasarkan American Diabetes Association (2019) menyatakan bahwa secara umum DM dibagi menjadi DM tipe 1 dan DM tipe 2 (Lewis, Bucher, Heitkemper, Harding, Kwong, 2016).

Salah satu tujuan dalam merawat pasien dengan diabetes mellitus tipe 2 adalah untuk menghilangkan gejala, mencegah dan memperlambat perkembangan terjadinya komplikasi (Khardori, 2020). Masalah yang mengancam kehidupan orang dengan diabetes mellitus tipe 2 yang tidak terkontrol adalah hiperglikemia dengan ketoasidosis atau sindrom hiperglikemia hyperosmolar nonketosis (hyperglycemic hyperosmolar nonketotic syndrome [HHNS] (Soelistijo et al., 2015). Komplikasi lainnya berupa meningkatnya penyakit jantung, stroke, neuropati, retinopati, gagal ginjal, dan penyebab kematian (Kemenkes RI, 2019).

Berdasarkan hasil survei diperoleh data bahwa secara global sebanyak 422 juta orang dewasa berusia di atas usia18 tahun hidup dengan diabetes mellitus pada tahun 2014. Hal ini juga didukung oleh data dari International Diabetes Federation (IDF) yang menyatakan bahwa terdapat 383 juta orang (175 juta diperkirakan belum terdiagnosis) di dunia yang menderita DM pada tahun 2013, dari jumlah ini diperkirakan akan semakin meningkat menjadi 592 juta orang di tahun 2035 (Kemenkes RI, 2019).
Peningkatan penyakit ini sebagian besar akan terjadi di Negara berkembang, hal ini dapat disebabkan oleh adanya beberapa faktor seperti: pertumbuhan penduduk, penuaan, diet tidak sehat dan gaya hidup yang menetap (WHO, 2016).

Indonesia adalah salah satu dari 21 negara dan wilayah International Diabetes Federation (IDF) dengan 425 juta orang menderita diabetes mellitus di dunia dan 159 juta orang dan pada tahun 2045 ini akan meningkat menjadi 183 juta. Ada lebih dari 10 juta kasus diabetes mellitus di Indonesia pada tahun 2017 yaitu jumlah populasi orang dewasa 166.513 juta, prevalensi diabetes pada orang dewasa sebanyak $6,7 \%$ sehingga total kasus diabetes pada orang dewasa adalah 10.276 juta (IDF, 2019).

Berdasarkan hasil data dari Dinas Kesehatan Kota Batam tahun 2018, penderita diabetes mellitus pada 17 Puskesmas di Kota Batam berjumlah 3.008 orang dengan prevalensi terbanyak di Puskesmas Tiban Baru yaitu dengan jumlah 439 orang atau 14,6\% (Dinas Kesehatan Kota Batam, 2018).

Berdasarkan hasil studi pendahuluan yang dilakukan dengan wawancara terpimpin pada 10 orang pasien diabetes mellitus tipe 2 di Puskesmas Tiban Baru, 7 dari 10 orang pasien diabetes mellitus tipe 2 tidak pernah melakukan pola makan yang seimbang sesuai dengan anjuran petugas kesehatan dan tidak bisa mengikuti diet untuk pasien diabetes mellitus tipe 2 dengan benar, pasien menyatakan jarang melakukan pengecekan gula darah dan latihan fisik atau olahraga setiap harinya.

Beberapa faktor penyebab meningkatnya kadar gula darah dibagi menjadi dua faktor yaitu faktor internal berupa penyakit stress, obesitas, asupan makan/pola makan, jumlah latihan fisik, perawatan tablet atau insulin, sedangkan berdasarkan faktor eksternal yaitu pendidikan, pengetahuan, dan kedekatan dan keterpaparan dengan sumber informasi. Jumlah kasus diabetes mellitus ini akan terus bertambah sejalan dengan adanya penurunan aktivitas fisik dan perubahan pola makan yang tidak sehat (Suiraoka, 2012). Pemeriksaan kadar gula darah sewaktu (GDS) lebih sering dilakukan untuk mengetahui naik/turunnya kadar gula darah pada penderita diabetes mellitus dalam waktu cepat dibandingkan dengan pemeriksaan 
kadar gula darah puasa (GDP) yang mana harus menyarankan pasien untuk berpuasa 2 jam setelah makan terlebih dahulu sebelum dilakukan pemeriksaan gula darah (Perkeni, 2019).

Berdasarkan dari hasil penelitian sebelumnya diperoleh data bahwa pola makan memiliki pengaruh sebesar $91 \%$ dan pola aktivitas fisik memiliki pengaruh sebesar $85 \%$ terhadap kadar gula darah sewaktupada pasien diabetes mellitus tipe 2 (Sudaryanto et al., 2014).

Penelitian lainnya menyatakan bahwa pola makan yang berlebihan dan melebihi jumlah kadar kalori yang dibutuhkan oleh tubuh dan aktivitas yang tidak banyak bergerak dapat meningkatkan kadar gula darah dan resiko terkena diabetes mellitus tipe 2 (Sami et al., 2017). Kurangnya aktivitas fisik merupakan faktor risiko independen untuk penyakit kronis dan secara keseluruhan diperkirakan menyebabkan kematian secara global (WHO, 2016).

\section{METODE PENELITIAN}

Penelitian menggunakan desain korelasi dengan rancangan penelitian cross sectional. Tujuan penelitian adalah untuk menganalisis hubungan antar variabel yang diteliti yaitu hubungan pola makan dan pola aktivitas fisik terhadap kadar gula darah sewaktu pada pasien diabetes mellitus tipe 2. Populasi dalam penelitian merupakan pasien dengan riwayat menderita diabetes mellitus tipe 2 yang berusia antara 20-79 tahun. Jumlah sampel dalam penelitian sebanyak 58 responden.Sampel diambil dengan teknik pengambilan purposive sampling. Alat pengumpulan datayang digunakan dalam penelitian menggunakan kuesioner pola makan, kuesioner pola aktivitas fisik, lembar observasi, dan alat glukometer. Prosedur pengolahan data yang dilakukan melalui tahap editing, coding, entry, cleaning, dan tabulasi data. Data dianalisa melalui proses analisa univariat dan analisa bivariat dengan menggunakan uji Mann-Whitney dengan tingkat kemaknaan $90 \%(\alpha \leq 0,05)$ yang berarti bahwa jika $\mathrm{p}<0,05$.

\section{HASIL DAN PEMBAHASAN}

3.1 Hasil

Analisa Univariat

Tabel 1. Distribusi Frekuensi Berdasarkan Usia

\begin{tabular}{lcc}
\hline \multicolumn{1}{c}{ Usia } & n & $\mathbf{\%}$ \\
\hline Dewasa awal $(26-35$ tahun $)$ & 9 & 15,5 \\
\hline Dewasa akhir $(36-45$ tahun $)$ & 18 & 31,0 \\
\hline Lansia awal $(46-55$ tahun $)$ & 19 & 32,8 \\
\hline Lansia akhir $(56-65$ tahun $)$ & 8 & 13,8 \\
\hline Manula (>65 tahun) & 4 & 6,9 \\
\hline \multicolumn{1}{c}{ Total } & 58 & 100 \\
\hline
\end{tabular}

Berdasarkan dari tabel 1, hasil penelitian didapatkan bahwa usia pasien diabetes mellitus tipe 2 sebanyak dari 19 orang $(32,8$

$\%)$ berusia termasuk kategori lansia awal (4655 tahun).

Tabel 2. Distribusi Frekuensi Berdasarkan Jenis Kelamin

\begin{tabular}{lcc}
\hline \multicolumn{1}{c}{ Jenis Kelamin } & n & \% \\
\hline Laki-laki & 20 & 34,5 \\
\hline Perempuan & 38 & 65,5 \\
\hline
\end{tabular}

Berdasarkan tabel 2, maka dapat diperoleh data bahwa jenis kelamin pasien diabetes mellitus tipe 2 sebanyak 38 orang $(65,5 \%)$. Tingginya angka perubahan kadar gula darah sewaktu diabetes mellitus tipe 2 pada perempuan dipengaruhi oleh beberapa faktor salah satunya, yaitu pola makan dan pola aktivitas fisik.

Tabel 3. Distribusi Frekuensi Berdasarkan Pekerjaan

\begin{tabular}{lcc}
\hline \multicolumn{1}{c}{ Pekerjaan } & n & \% \\
\hline Ibu Rumah Tangga & 22 & 37,9 \\
\hline Penjaga Toko & 8 & 13,8 \\
\hline Buruh Pabrik & 14 & 24,1 \\
\hline Kerja Bangunan & 4 & 6,9 \\
\hline Pekerja Konstruksi & 9 & 15,5 \\
\hline Instruktur Senam & 1 & 1,7 \\
\hline Total & 58 & 100 \\
\hline \multicolumn{1}{c}{ Berdasarkan hasil } & tabel & 3
\end{tabular}
diperoleh data bahwa pekerjaan pasien diabetes mellitus tipe 2 adalah sebanyak 22 orang $(37,9 \%)$ bekerja sebagai ibu rumah tangga. Pekerjaan ibu rumah tangga dalam penelitian ini adalah ibu rumah tangga yang hanya duduk santai dan tidak banyak melakukan pekerjaannya sebagai ibu rumah tangga seperti mencuci, menyapu, membersihkan rumah, dan sebagainya dalam setiap harinya, sehingga dengan aktifitas yang kurang menyebabkan ibu rumah tangga 
dalam penelitian ini lebih banyak yang mengalami kadar gula darah sewaktu yang tinggi.

Tabel 4. Distribusi Frekuensi Berdasarkan Lama Riwayat Menderita

\begin{tabular}{lcc}
\hline $\begin{array}{c}\text { Riwayat menderita DM Tipe } \\
\text { Keturunan }\end{array}$ & n & \% \\
\hline$>5$ tahun & 27 & 46,6 \\
\hline$\leq 5$ tahun & 21 & 36,2 \\
\hline Total & 10 & 17,2 \\
\hline \multicolumn{1}{c}{ Berdasarkan tabel 4} & 58 & 100 \\
\hline
\end{tabular}

Berdasarkan tabel 4 diperoleh data bahwa jumlah pasien dengan riwayat menderita diabetes mellitus tipe 2 yang memiliki riwayat keturunan yaitu sebanyak 27 orang $(46,6 \%)$.

Tabel 5. Distribusi Frekuensi Berdasarkan

\begin{tabular}{lcc}
\multicolumn{2}{c}{ Pola Makan } \\
\hline \multicolumn{1}{c}{ Pola Makan } & n & \% \\
\hline Seimbang & 17 & 29,3 \\
\hline Tidak Seimbang & 41 & 70,7 \\
\hline Total & 58 & 100 \\
\hline
\end{tabular}

Berdasarkan tabel 5 diperoleh data bahwa mayoritas pasiendiabetes mellitus tipe 2 mempunyai pola makanyang tidak seimbang yaitu sebanyak 41 orang $(70,7 \%)$, dan pasien yang memiliki pola makan seimbang sebanyak 17 orang $(29,3 \%)$.
Tabel 6. Distribusi Frekuensi Berdasarkan Pola Aktivitas Fisik

\begin{tabular}{lcc}
\hline \multicolumn{1}{c}{ Pola Aktivitas Fisik } & n & \% \\
\hline Ringan & 35 & 60,3 \\
\hline Sedang & 23 & 39,7 \\
\hline Total & 58 & 100 \\
\hline
\end{tabular}

Berdasarkan tabel 6 dapat dilihat bahwa mayoritas pasien diabetes mellitus tipe 2 mempunyai pola aktivitas yang ringan yaitu sebanyak 35 orang $(60,3 \%)$, dan pasien yang memiliki pola aktivitas sedang sebanyak 23 orang $(39,7 \%)$.

Tabel 7. Distribusi Frekuensi Berdasarkan Kadar Gula Darah Sewaktu (GDS)

\begin{tabular}{lcc}
\hline $\begin{array}{c}\text { Kadar Gula Darah } \\
\text { Sewaku (GDS) }\end{array}$ & $\mathbf{n}$ & $\boldsymbol{\%}$ \\
\hline Normal & 3 & 5,2 \\
\hline Sedang & 16 & 27,6 \\
\hline Tinggi & 39 & 67,2 \\
\hline Total & 58 & 100 \\
\hline
\end{tabular}

Berdasarkan tabel 7 dapat dilihat bahwa mayoritas pasien diabetes mellitus tipe 2 mempunyai kadar gula darah sewaktu yang tinggi sebanyak 39 orang $(67,2 \%)$, dan pasien yang memiliki kadar gula darah sewaktu yang normal sebanyak 3 orang $(5,2 \%)$.

\section{Analisa Bivariat}

Tabel 8. Distribusi Frekuensi Berdasarkan Hubungan Pola Makan terhadap Kadar Gula Darah Sewaktu (GDS)

\begin{tabular}{|c|c|c|c|c|c|c|c|c|c|}
\hline \multirow[t]{3}{*}{ Pola Makan } & \multicolumn{6}{|c|}{ Kadar Gula Darah Sewaktu (GDS) } & \multirow{2}{*}{\multicolumn{2}{|c|}{ Total }} & \multirow[t]{2}{*}{ P Value } \\
\hline & \multicolumn{2}{|c|}{ Normal } & \multicolumn{2}{|c|}{ Sedang } & \multicolumn{2}{|c|}{ Tinggi } & & & \\
\hline & $\mathrm{N}$ & $\%$ & $\mathrm{~N}$ & $\%$ & $\mathrm{~N}$ & $\%$ & $\mathrm{~N}$ & $\%$ & 0,000 \\
\hline Seimbang & 1 & 5,9 & 15 & 88,2 & 1 & 5,9 & 17 & 100 & \\
\hline Tidak Seimbang & 2 & 4,9 & 1 & 2,4 & 38 & 92,7 & 41 & 100 & \\
\hline Jumlah & 3 & 5,2 & 16 & 27,6 & 39 & 67,2 & 58 & 100 & \\
\hline
\end{tabular}

Berdasarkan tabel 8 diatas dapat dilihat bahwa pasien diabetes mellitus tipe 2 sebanyak 38 orang $(92,7 \%)$ yang memiliki pola makan tidak seimbang dengan kadar gula darah yang tinggi.

Tabel 9. Distribusi Frekuensi Berdasarkan Hubungan Pola Aktivitas Fisik terhadap Kadar Gula Darah Sewaktu (GDS)

\begin{tabular}{|c|c|c|c|c|c|c|c|c|c|}
\hline \multirow{3}{*}{$\begin{array}{c}\text { Pola Aktivitas } \\
\text { Fisik }\end{array}$} & \multicolumn{6}{|c|}{ Kadar Gula Darah Sewaktu (GDS) } & \multirow{2}{*}{\multicolumn{2}{|c|}{ Total }} & \multirow{3}{*}{$\begin{array}{c}\mathbf{P} \\
\text { Value } \\
0,000\end{array}$} \\
\hline & \multicolumn{2}{|c|}{ Normal } & \multicolumn{2}{|c|}{ Sedang } & \multicolumn{2}{|c|}{ Tinggi } & & & \\
\hline & $\mathbf{N}$ & $\%$ & $\mathbf{N}$ & $\%$ & $\mathbf{N}$ & $\%$ & $\mathbf{N}$ & $\%$ & \\
\hline Ringan & 1 & 2,9 & 2 & 5,7 & 32 & 91,4 & 35 & 100 & \\
\hline Sedang & 2 & 8,7 & 14 & 60,9 & 7 & 30,4 & 23 & 100 & \\
\hline Jumlah & 3 & 5,2 & 16 & 27,6 & 39 & 67,2 & 58 & 100 & \\
\hline
\end{tabular}


Berdasarkan tabel 9 didapatkan data sebanyak 32 orang pasien diabetes mellitus tipe $2(91,4 \%)$ memiliki pola aktivitas fisik ringan dengan kadar gula darah yang tinggi.

\subsection{Pembahasan}

\section{Pola Makan Pasien Diabetes Mellitus Tipe} 2

Sebaiknya dalam mengontrol pola makan lebih baik membuat jadwal makanan setiap hari untuk membuat variasi pada setiap menu makanan yang akan dikonsumsi setiap hari agar lebih mudah dalam pemenuhan pola makan yang seimbang pada penderita diabetes mellitus tipe 2 .

\section{Pola Aktivitas Fisik Pasien Diabetes Mellitus Tipe 2}

Semakin banyak aktivitas yang dilakukan dalam sehari akan banyak menguntungkan dalam hal kesehatan terutama pada pasien diabetes mellitus tipe 2 yaitu dapat mengontrol kadar gula darah sewaktu pada batas normal dan stabil.

\section{Kadar Gula Darah Sewaktu (GDS) Pasien Diabetes Mellitus Tipe 2}

Beberapa faktor yang mempengaruhi kadar gula darah sewaktu menurut (Qurratuaeni, 2009) antara lain dibagi menjadi 2 yaitu faktor internal berupa penyakit dan stress, obesitas, asupan/pola makan, jumlah latihan fisik/pola aktivitas fisik dan penggunaan obat tablet maupun insulin dengan faktor eksternal yaitu pendidikan, pengetahuan, kedekatan,dan keterpaparan dengan sumber informasi. Pengontrolan kadar gula darah sewaktu bisa dilakukan salah satunya dengan cara melakukan pola makan dan pola aktivitas fisik sesuai dengan ketentuan untuk penderita diabetes mellitus tipe 2 .

\section{Analisa Bivariat}

\section{Pola Makan Terhadap Kadar Gula Darah} Sewaktu (GDS) Pasien Diabetes Mellitus Tipe 2

Berdasarkan hasil uji Mann-Whitney diperoleh bahwa nilai $\rho=0,000$ untuk variabel independent yaitu pola makan dengan nilai $\rho<0,05$ Ha diterima sedangkan $\mathrm{H}_{0}$ ditolak, hal ini menunjukkan bahwa terdapat hubungan yang signifikan antara pola makan terhadap kadar Gula Darah Sewaktu pada pasien diabetes mellitus tipe 2 .

Hasil penelitian ini sejalan dengan penelitian (Cholifah et al., 2016) menyatakan bahwa pasien diabetes mellitus tipe 2 dengan pola makan yang buruk dan dengan kadar gula darah sewaktu yang tinggi (buruk) sebanyak 7 orang pasien diabetes mellitus tipe $2(50,0 \%)$, sejalan dengan penelitian yang dilakukan oleh (Dolongseda et al., 2017) bahwa sebanyak 43 orang $(57,3 \%)$ memiliki pola makan yang tidak baik dan kadar gula darah sewaktu yang tinggi, begitu juga dengan penelitian (Firmansyah, 2014) bahwa sebanyak 32 orang pasien diabetes mellitus tipe $2(35,9 \%)$ memiliki pola makan yang tidak baik dengan kadar gula darah sewaktu yang tinggi.

Pola makan menurun seiring bertambahnya usia, hal itu dikarenakan semakin bertambahnya usia, maka pasien akan semakin menurunnya metabolisme dan kemampuan tubuh manusia dalam melakukan aktivitas (Sulistyoningsih, 2011). Pengontrolan kadar gula darah sewaktu sangat penting dalam pengaturan pola makan seimbang baik jumlah, frekuensi, banyak dan juga kandungannya sehingga tubuh dapat mengatur kadar glukosa darah agar tidak terlalu tinggi atau terlalu rendah pada penderita diabetes mellitus tipe 2 .

Pola Aktivitas Fisik Terhadap Kadar Gula Darah Sewaktu (GDS) Pasien Diabetes Mellitus Tipe 2

Berdasarkan hasil uji Mann-Whitney diperoleh bahwa nilai $\rho=0,000$ untuk variabel independent yaitu pola aktivitas fisik dengan nilai $\rho<0,05 \mathrm{Ha}$ diterima sedangkan $\mathrm{H}_{0}$ ditolak, hal ini menunjukkan bahwa terdapat hubungan yang signifikan antara pola aktivitas fisik terhadap kadar gula darah sewaktu pada pasien diabetes mellitus tipe 2 . Sangat baik melakukan aktivitas fisik dalam kehidupan sehari-hari guna mengontrol kadar gula darah sewaktu pada seseorang dengan diabetes mellitus tipe 2 dan melakukannya dengan rutin.

\section{KESIMPULAN}

Berdasarkan hasil penelitian dapat disimpulkan bahwa terdapat hubungan yang signifikan antara pola makan dan pola aktivitas fisik terhadap kadar gula darah 
sewaktu pada pasien diabetes mellitus tipe 2 dengan nilai $\mathrm{p}$ value $0,000(\alpha=0,05)$ untuk masing-masing variabel. Bagi pasien diabetes mellitustipe 2 disarankan untuk mengatur dan menjaga pola makan seimbang baik jumlah, frekuensi, dan kandungan yang dikonsumsi setiap harinya dengan melakukan konsultasi di pelayanan kesehatan, melakukan aktivitas fisik secara rutin dalam kehidupan seharihari, serta melakukan pemeriksaan kadar gula darah mandiri secara rutin untuk menjaga kadar gula darah dalam batas normal dan stabil.

\section{REFERENCES}

American Diabetes Association. (2019). Standards of Medical Care in Diabetes. In American Diabetes Association: Vol. (5)2 (Issue 2, pp. 285-299).

Cholifah, N., Azizah, N., \& Indanah. (2016). Hubungan antara Pola Makan dan Aktivitas Fisik dengan Kadar GDS pada Pasien Diabetes Mellitus (DM) Tipe II di Puskesman Mayong II Jepara Tahun 2015. Jikk, 7(2), 01-79.

Dinas Kesehatan Kota Batam. (2018). Profil kesehatan kota batam (Issue 7). Dinas Kesehatan Kota Batam.

Dolongseda, F., Massie, G., \& Bataha, Y. (2017). Hubungan Pola Aktivitas Fisik Dan Pola Makan Dengan Kadar Gula Darah Pada Pasien Diabetes Melitus Tipe Ii Di Poli Penyakit Dalam Rumah Sakit Pancaran Kasih Gmim Manado. Jurnal Keperawatan UNSRAT, 5(1), 105542.

Firmansyah, M. R. (2014). Hubungan Pola Makan Dan Aktivitas Fisik Dengan Kadar Gula Darah Penderita Diabetes Melitus Tipe Ii Di Puskesmas 7 Ulu Kota Palembang. Seminar Workshop Nasional, 2012, 218-222.

IDF. (2019). Diabetes Atlas Ninth Edition English : International Diabetes Federation

Kemenkes RI. (2019). Profil Kesehatan Indonesia 2018 [Indonesia Health Profile 2018]. http://www.depkes.go.id/resources/down load/pusdatin/profil-kesehatanindonesia/Data-dan-Informasi_ProfilKesehatan-Indonesia-2018.pdf

Khardori, R. (2020). Type 2 Diabetes Mellitus Treatment \& Management.
Medscape.Com.

https://emedicine.medscape.com/article/ 117853-treatment

Lewis.S, Bucher.L Heitkemper Margaret Mariann Harding, Dottie J.K, R. (2016). Medical Surgical Nursing 10th edition. Elsevier.

Marewa, L. W. (2015). Kencing Manis (Diabetes Mellitus) di Sulawesi Selatan. Yayasan Pustaka Obor Indonesia. https://books.google.co.id/books?id=SIR EDAAAQBAJ\&printsec $=$ frontcover\&hl $=i d \&$ source $=g b s$ ge_summary_r $\&$ cad $=0$ \# $\mathrm{v}=$ onepage $\& \mathrm{q} \& \mathrm{f}=$ false

Perkeni. (2019). Pedoman Pemantauan Glukosa Darah Mandiri. Jakarta : PB. PERKENI.

Qurratuaeni. (2009). Faktor-Faktor Yang Berhubungan Dengan Terkendalinya Kadar Gula Darah Pada Pasien Diabetes Mellitus Di Rumah Sakit Umum Pusat (Rsup) Fatmawati Jakarta Tahun 2009. Uin Syarif Hidayatullah, 31-35.

Sami, W., Ansari, T., Butt, N. S., Rashid, M., \& Hamid, A. (2017). Effect of diet on type 2 diabetes mellitus: A review. International Journal of Health Sciences, 11(2).

Soelistijo, S., Novida, H., Rudijanto, A., Soewondo, P., Suastika, K., Manaf, A., Sanusi, H., Lindarto, D., Shahab, A., Pramono, B., Langi, Y., Purnamasari, D., \& Soetedjo, N. (2015). Konsesus Pengelolaan Dan Pencegahan Diabetes Melitus Tipe2 Di Indonesia 2015. In Perkeni.

https://www.google.com/url?sa=t\&sourc $\mathrm{e}=$ web\&rct=j\&url=https://pbperkeni.or.i d/wp-content/uploads/2019/01/4.-

Konsensus-Pengelolaan-dan-

Pencegahan-Diabetes-melitus-tipe-2-diIndonesia-

PERKENI2015.pdf\&ved=2ahUKEwjy8 KOs8cfoAhXCb30KHQb1Ck0QFjADe gQIBhAB\&usg=AOvVaw1PxTUAnZL MkJYCkfCBY1mU

Sudaryanto, A., Setiyadi, Alis, N., \& Frankilawati, Ayu, D. (2014). Hubungan antara Pola Makan, Genetik dan Kebiasaan Kerja Puskesmas Nusukan, Banjasari. Prosiding SNST, 3, 19-24.

Suiraoka. (2012). Penyakit Degeneratif: mengenal, mencegah dan mengurangi 
faktor risiko 9 penyakit degeneratif. $\quad$ WHO. (2016). World Health Statistics 2016. Jakarta: Nuha Medika.

Global Report on Diabetes.

Sulistyoningsih, H. (2011). Gizi untuk

Kesehatan Ibu dan Anak. Jakarta: Graha

Ilmu.

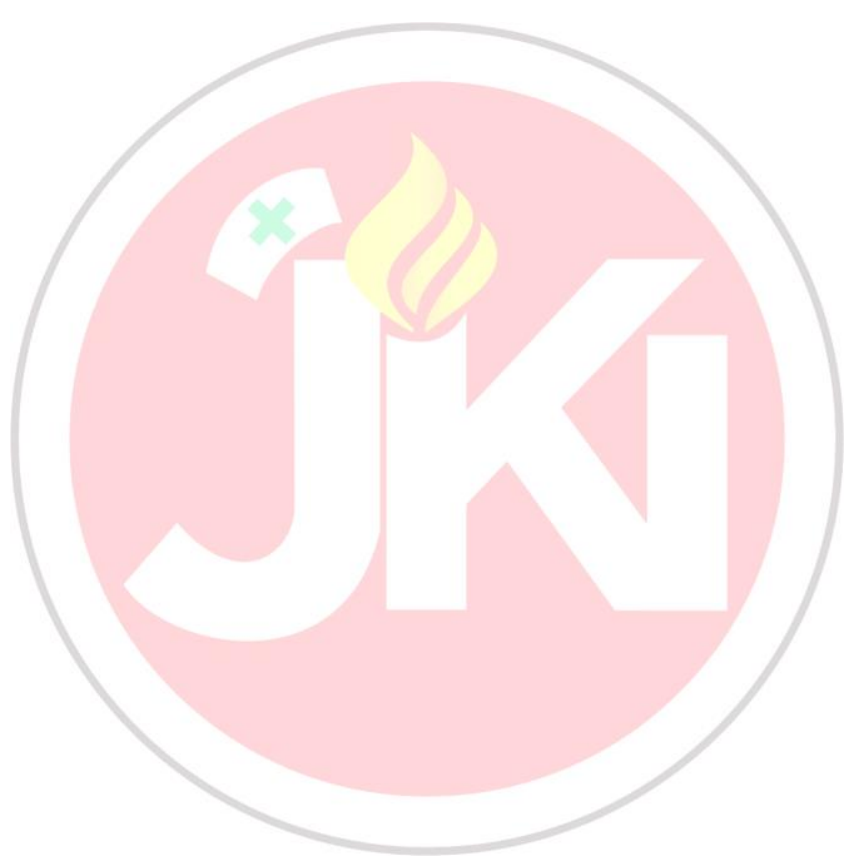

